\title{
Early Enriched Environment Promotes Neonatal GABAergic Neurotransmission and Accelerates Synapse Maturation
}

\author{
Shan $\mathrm{He},{ }^{1,2 *} \mathrm{Jun} \mathrm{Ma}^{1 \star} \mathrm{Na} \mathrm{Liu},{ }^{1,2}$ and Xiang $\mathrm{Yu}^{1}$ \\ ${ }^{1}$ Institute of Neuroscience and State Key Laboratory of Neuroscience, Shanghai Institutes for Biological Sciences, Chinese Academy of Sciences, Shanghai \\ 200031, China, and 2Graduate School of the Chinese Academy of Sciences, Shanghai 200031, China
}

Environmental stimulation is critical for brain development. Here, we report that natural stimulation through enriched environment (EE) rearing during the first 2 weeks of mouse postnatal development promotes GABAergic neurotransmission and accelerates maturation of GABAergic and glutamatergic synapses. Using whole-cell recordings from CA1 pyramidal neurons in acute hippocampal slices, we found that EE-reared mice exhibited higher amplitude of miniature GABAergic postsynaptic currents (mGPSCs) at 1 week of postnatal development, as well as accelerated transition of GABA action from excitation to inhibition, compared with mice reared under standard housing conditions. This enhanced GABAergic synaptic transmission persisted until the end of the second postnatal week, when GABA mostly acts as an inhibitory neurotransmitter. Consistent with these electrophysiological results, we observed elevated levels of $\mathrm{GABA}_{\mathrm{A}}$ receptors and the $\mathrm{K}^{+}-\mathrm{Cl}^{-}$cotransporter KCC2. Similarly, increased levels of excitatory synaptic components, including NMDA and AMPA receptors and the scaffolding protein PSD95, were detected in synaptosomal fractions from the forebrain/hippocampus of EEreared mice during the first two postnatal weeks. Functional increase in glutamatergic synaptic transmission, as measured by increased amplitude of miniature and spontaneous EPSCs, was also detected during the second postnatal week. Together, these results demonstrate that early environmental stimulation through EE rearing enhances early postnatal GABAergic neurotransmission, which is known to play important trophic functions in many aspects of neural development.

\section{Introduction}

Rearing animals in an enriched environment (EE) is a classic paradigm that has been used extensively in juvenile and adult rodents for studying the effect of a combination of complex inanimate and social stimulations (Bennett et al., 1964; Rosenzweig et al., 1978). By examining the effects of environmental stimulation after weaning or during adulthood, previous studies demonstrated that this paradigm can elicit structural and functional changes in the nervous system, including increases in dendritic arborization and spine density, synaptic protein expression, synaptic plasticity, and neurogenesis (Rosenzweig and Bennett, 1996; van Praag et al., 2000; Nithianantharajah and Hannan, 2006; Sale et al., 2009). Recent studies showed that EE rearing of neonatal pups accelerated development of the visual system, as assayed by behavioral visual acuity and changes in visual cortical plasticity (Cancedda et al., 2004; Sale et al., 2009). Conversely, visual deprivation by dark rearing during the critical period (3-5

Received Dec. 24, 2009; revised April 21, 2010; accepted April 27, 2010.

This work was supported by grants from the Ministry of Science and Technology (2006CB806600, 2006CB943900), the Natural Science Foundation of China (30721004), and the Chinese Academy of Sciences (Hundred Talent Program and KSCX2-YW-R-103). We thankL. Devito, H. Eichenbaum, M. Sauvage, and L. Xu for advice on establishing the enriched environment paradigm. We thank J.-J. Cai, Y. Lu, and J.-C. Liu for excellent technical assistance, J. Hao, H.-K. Wang, C. Xu, X.-H. Zhang, and Y. Zhou for advice on electrophysiological recordings, and G. Thomas for advice on synaptosomal preparations. We are grateful to faculty members at the Institute of Neuroscience and members of the Yu lab for suggestions and discussions and M.-M. Poo for thoughtful comments on the manuscript.

*S.H. and J.M. contributed equally to this work.

Correspondence should be addressed to Xiang Yu at the above address. E-mail: yuxiang@ion.ac.cn.

D0I:10.1523/JNEUROSCI.6375-09.2010

Copyright $\odot 2010$ the authors $\quad 0270-6474 / 10 / 307910-07 \$ 15.00 / 0$ postnatal weeks) stalled development of GABAergic synapses in the visual cortex (Morales et al., 2002) and altered ocular dominance plasticity (Hensch, 2005; Jiang et al., 2005). Thus, environmental stimulation plays a critical role in neural circuit formation and function (van Praag et al., 2000; Fox and Wong, 2005; Hensch, 2005; Nithianantharajah and Hannan, 2006; Sale et al., 2009).

To study the earliest effect of environmental stimulation on neural circuit development, we investigated the effects of neonatal EE rearing on the electrophysiological and biochemical properties of GABAergic and glutamatergic synapses in the hippocampus. We found that EE rearing enhanced GABAergic neurotransmission as early as 1 week after birth, when GABA largely acts as an excitatory neurotransmitter (Ben-Ari et al., 1989; BenAri, 2002; Owens and Kriegstein, 2002). This enhancement of GABAergic synaptic transmission in EE-reared mice was accompanied by accelerated transition of GABA action from excitation to inhibition and persisted until the second postnatal week. Increased glutamatergic neurotransmission was only detected at postnatal day 14 (P14). Our results underscore the importance of neonatal natural stimulation on neural development by demonstrating that EE rearing promotes the maturation of both GABAergic and glutamatergic synapses and enhances GABAergic neurotransmission, an important regulator of early development.

\section{Materials and Methods}

Animals and EE rearing paradigm. All animal studies were approved by the Institutional Animal Care and Use Committee of the Institute of Neuroscience, Chinese Academy of Sciences (Shanghai, China). The environmental enrichment paradigm for neonatal mice was based on a previous protocol (Cancedda et al., 2004) with additional tactile and 
olfactory stimuli. Briefly, C57BL/6 timed pregnant mice [embryonic days 16-20 (E16-20)] were randomly assigned to standard or EE housing 4-7 $\mathrm{d}$ before delivery. All mice were exposed to a $12 \mathrm{~h}$ light/12 h dark cycle with food and water provided ad libitum from the cage lid. The enriched housing consists of a large Plexiglas laboratory cage $(50 \times 36 \times 28 \mathrm{~cm})$ containing objects of various shapes and textures (wooden or plastic houses, igloos, tunnels, and wood blocks) repositioned daily and completely substituted weekly; a running wheel was added at P11. Object positions and combinations were not repeated. Additional bedding materials (shredded paper, paper roll, cotton, or textiles of various textures) were added to stimulate somatosensation and changed daily. A spice cube containing different spices was added to varying positions in the cage to stimulate olfactory responses and changed daily. Two dams with their litters (10 pups minimum) were placed in EE cages, while one dam and its litter were placed in standard control cages $(32.5 \times 21 \times 18.5 \mathrm{~cm})$ lined only with corn bedding.

Electrophysiological recordings. Mice were deeply anesthetized with $0.7 \%$ sodium pentobarbital, and slices were prepared as described previously (van Praag et al., 2002). Briefly, brains were rapidly removed and immersed in ice-cold dissection buffer containing the following (in $\mathrm{mM}$ ): 110 choline-Cl, $2.5 \mathrm{KCl}, 1.3 \mathrm{NaH}_{2} \mathrm{PO}_{4}, 7 \mathrm{MgCl}_{2}, 0.5 \mathrm{CaCl}_{2}, 25 \mathrm{NaHCO}_{3}$, 20 glucose, bubbled with $95 \% \mathrm{O}_{2} / 5 \% \mathrm{CO}_{2}, \mathrm{pH}$ 7.4. Hippocampal slices were cut at $350 \mu \mathrm{m}$ using a Vibratome 3000 (Leica) microslicer and allowed to recover in a submersion holding chamber with artificial CSF (ACSF) containing the following (in $\mathrm{mm}$ ): $125 \mathrm{NaCl}, 2.5 \mathrm{KCl}, 1.3$ $\mathrm{NaH}_{2} \mathrm{PO}_{4}, 1.3 \mathrm{MgCl}_{2}, 2 \mathrm{CaCl}_{2}, 25 \mathrm{NaHCO}_{3}, 20$ glucose 20, bubbled with $95 \% \mathrm{O}_{2} / 5 \% \mathrm{CO}_{2}$ mixture for at least $1 \mathrm{~h}$ before recordings. Slices were visualized with an upright microscope (Nikon FN1) equipped with infrared differential interference contrast and perfused with oxygenated $\mathrm{ACSF}$ at $25^{\circ} \mathrm{C}$. Whole-cell voltage-clamp recordings were made from CA1 pyramidal cells with a MultiClamp 700B amplifier (Molecular Devices). Signals were filtered at $2 \mathrm{kHz}$ and sampled at $10 \mathrm{kHz}$ using Digidata 1332A (Molecular Devices) in all experiments.

For miniature GABAergic postsynaptic current (mGPSC) recordings, glass pipettes (resistance 3-5 M 2 ) were loaded with a high chloride internal solution containing the following (in mM): $110 \mathrm{CsCl}, 10 \mathrm{NaCl}, 5$ $\mathrm{MgCl}_{2}$, 0.6 EGTA, $2 \mathrm{MgATP}, 0.2 \mathrm{Na}_{3} \mathrm{GTP}, 40$ HEPES; cells were held at -60 mV. NBQX (1,2,3,4-tetrahydro-6-nitro-2,3-dioxo-benzo[f]quinoxaline-7-sulfonamide) at $10 \mu \mathrm{m}$ and TTX at $0.5 \mu \mathrm{m}$ were added to ACSF to block AMPA and $\mathrm{Na}^{+}$currents, respectively. For $E_{\mathrm{Cl}}$ recordings, pipettes were tip filled with internal solution containing the following (in mM): $\mathrm{CsCl} 154, \mathrm{NaCl} 9, \mathrm{MgCl}_{2}$ 1, HEPES 10, and EGTA 0.2 (pH 7.4, 300 mOsm); the pipettes were back filled with the same internal solution containing $10-20 \mu \mathrm{g} / \mathrm{ml}$ gramicidin A. Kyneurenic acid at $2 \mathrm{~mm}$ was added to ACSF to block glutamatergic transmission. GABAergic responses were evoked by stimulating nearby interneurons (Xu et al., 2008) with a bipolar tungsten stimulating electrode (WPI). Responses were evoked with a Master-8 pulse generator coupled through an Iso-Flex isolator (A.M.P.I.). $E_{\mathrm{Cl}}$ was determined by measuring the amplitudes of GPSCs at stepped holding membrane potentials ( $10 \mathrm{mV}$ increments) of the postsynaptic cell. Linear regression was used to calculate a best-fit line for the voltage dependence of GPSC amplitude, and the interpolated intercept of this line with the abscissa was taken as the $E_{\mathrm{Cl}}$ value.

For EPSC recordings, the internal solution contained the following (in mm): $\mathrm{CsMeSO}_{4}$ 100, CsCl 25.5, HEPES 10, $\mathrm{NaCl} 8$, EGTA 0.25, glucose 10, MgATP 4, $\mathrm{Na}_{3}$ GTP 0.3, pH 7.3 (280-290 mOsm); neurons were held at $-70 \mathrm{mV}$ unless stated otherwise. In all experiments, $50 \mu \mathrm{M}$ picrotoxin was added to ACSF to block $\mathrm{GABA}_{\mathrm{A}}$ synaptic currents, and $0.5 \mu \mathrm{M}$ TTX was added for miniature EPSC ( $\mathrm{mEPSC}$ ) recordings. EPSCs were evoked with a bipolar tungsten stimulating electrode (WPI) placed in the stratum radiatum near the stratum pyramidale border to activate proximal Schaffer collateral-CA1 synapses. Cells were held at $-70 \mathrm{mV}$ to record AMPA receptor (AMPAR) EPSCs and at $+40 \mathrm{mV}$ to record NMDA receptor (NMDAR) EPSCs. EPSC amplitudes were calculated by averaging 15-30 traces and measuring at the peak for the AMPAR component and $40 \mathrm{~ms}$ after the onset for the NMDAR component. Action potential frequency versus injected current curves were plotted by measuring, in current-clamp mode, the average action potential firing rate during 300 $\mathrm{ms}$ depolarizing current injections of increasing magnitude. Synaptic blockers [50 $\mu \mathrm{M}$ D-(-)-2-amino-5-phosphonovaleric acid (D-APV), 10 $\mu \mathrm{M}$ NBQX, and $50 \mu \mathrm{m}$ picrotoxin] were included as indicated. The internal solution for this experiment contained the following (in $\mathrm{mM}$ ): 110 K-gluconate, $20 \mathrm{KCl}, 20 \mathrm{HEPES}, 5 \mathrm{MgCl}_{2}$, 0.6 EGTA, $2 \mathrm{MgATP}, 0.2$ $\mathrm{Na}_{3} \mathrm{GTP}$, pH 7.3 (280-290 mOsm). All salts and drugs were obtained from Sigma or Tocris Bioscience, except for TTX, which was obtained from the Fisheries Science and Technology Development Company of Hebei Province, China.

Series and input resistances were continually monitored throughout all experiments. Data were not included if the series resistance changed by $>20 \%$ during the experiment. Miniature postsynaptic currents (mPSCs) were analyzed using MiniAnalysis software (Synaptosoft), and other data were analyzed using pClamp 9.2. To obtain accurate measures of the amplitude and kinetics of mPSCs, double peaks were excluded for the analysis of these parameters. The amplitude threshold for mGPSCs and mEPSCs were 6 and 5 pA, respectively, and the baseline was averaged over $5000 \mu$ s. Results were statistically tested using two-tailed Student's $t$ test; cumulative distributions were tested against each other using the Kolmogorov-Smirnov two-sample test. For cumulative distribution plots, 100 events per cell were used, except for mEPSCs at P18, for which 50 events were used. Results are shown as mean \pm SEM, and $n$ represents the number of neurons. At least three animals from different litters were analyzed per experimental condition. The $\mathrm{P} 7$ group included $\mathrm{P} 7-\mathrm{P} 9$ mice and the $\mathrm{P} 14$ group included $\mathrm{P} 13-\mathrm{P} 15$ mice, while the $\mathrm{P} 18$ group included $\mathrm{P} 17-\mathrm{P} 18$ mice. For $E_{\mathrm{Cl}}$ recordings, mice were analyzed separately according to gender. For all other experiments, the data from males and females were pooled.

Crude synaptosomal preparations and immunoblot analysis. Forebrains or hippocampi were dissected from age-matched P7 or P14 mice litters reared in control and EE conditions, and synaptosomes were prepared essentially as described previously (Luo et al., 1997; Hallett et al., 2008). Briefly, brains were homogenized in ice-cold HEPES-buffered sucrose (0.32 M sucrose, 4 mm HEPES, pH 7.4) containing freshly added protease inhibitor cocktail tablets (Roche) and centrifuged at $1000 \times g$ for $10 \mathrm{~min}$ to remove the pelleted nuclear fraction ( $\mathrm{P} 1$, used to assay c-Fos). The supernatant was then centrifuged at $10,000 \times g$ for 15 min to yield the membrane fraction pellet [P2, used for brain-derived neurotrophic factor (BDNF) and P7 hippocampal samples; nonboiled P2 sample was used for KCC2]. After a hypo-osmotic shock in pure water, the lysate was centrifuged at 25,000 $\times g$ for $20 \mathrm{~min}$. The pellet was then resuspended, loaded onto a discontinuous sucrose gradient $(0.8,1.0$, and $1.2 \mathrm{M})$ and centrifuged at 30,000 rpm for $2 \mathrm{~h}$. The synaptosomal fraction (all other proteins) was collected from the interface between the 1.0 and $1.2 \mathrm{M}$ sucrose layers. Proteins $(10-20 \mu \mathrm{g})$ were loaded onto SDS-PAGE, and Western blots were performed according to standard protocols. The following primary antibodies were used at the concentrations given: $\mathrm{GABA}_{\mathrm{A}} \mathrm{R} \alpha 1$ at 1:2000 (Millipore), KCC2 at 1:3000 (Millipore), GluR2 at 1:1000 (Millipore), BDNF at 1:500 (Santa Cruz Biotechnology), c-Fos at 1:500 (Santa Cruz Biotechnology), GAPDH at 1:10,000 (KangChen Biotech), NR2A at 1:100 (Millipore), NR2B at 1:1000 (Millipore), PSD95 at $1: 1000$ (Sigma), TBP at 1:1000 (Abcam), and $\alpha$-tubulin at 1:2,000,000 (Sigma). HRP-conjugated secondary goat anti-rabbit or goat anti-mouse antibodies (Millipore) were used at 1:8000. Blots were developed using ECL chemiluminescence substrate (Pierce) onto x-ray films (Kodak). Results were quantified using ImageJ software (NIH Image) and statistically analyzed using the Mann-Whitney rank sum test. Values for EEreared mice are normalized to those of controls. Results are shown as mean \pm SEM, and $n$ represents the number of matching litter pairs.

\section{Results}

Postnatal EE rearing enhances GABAergic neurotransmission To stimulate neonatal mice pups through multiple sensory modalities, we adapted a previously published EE-rearing protocol (Cancedda et al., 2004) with additional tactile and olfactory cues (see Materials and Methods). To determine whether this paradigm increased neural activity in vivo, we assayed the levels of BDNF (Poo, 2001; Pham et al., 2002; Cancedda et al., 2004; Matsumoto et al., 2008) and the transcription factor c-Fos 
(Flavell and Greenberg, 2008), proteins known to be regulated by activity, in forebrain extracts from P7 pups. We showed that the levels of both proteins were significantly elevated in EE-reared mice (supplemental Fig. 1A, $B$, available at www. jneurosci.org as supplemental material), suggesting that our natural stimulation paradigm had significantly increased neural activity at this very early developmental stage.

We next examined the effects of EE rearing on GABAergic neurotransmission during the developmental window from P7 to P18 by recording synaptic currents from CA1 pyramidal neurons of acute hippocampal slices. At P7, when $75 \%$ of neurons exhibited giant depolarizing potentials (supplemental Fig. 2, available at www.jneurosci.org as supplemental material) characteristic of the excitatory action of GABA (Ben-Ari et al., 1989; Ben-Ari, 2002; Owens and Kriegstein, 2002), EE rearing significantly increased the amplitude of mGPSCs (EE: $32.76 \pm 0.94 \mathrm{pA}$, control: $26.08 \pm 1.09$ pA, $p<0.0001$ ) (Fig. $1 A, G$ ). At P14, significantly higher frequency of mGPSCs (Fig. $1 B, E, H)$ (EE: $3.20 \pm 0.27 \mathrm{pA}$, control: $2.20 \pm 0.21 \mathrm{pA}, p=0.005)$ were observed in EE-reared mice, indicating a higher level of GABAergic transmission.

General characteristics of the maturation of GABAergic synapses (Hollrigel and Soltesz, 1997; Dunning et al., 1999; Huntsman and Huguenard, 2000; Banks et al., 2002), including developmental increases in mGPSC frequency, reduction in mGPSC amplitude, and faster kinetics (Fig. 1G,H; Table 1) were observed in both groups. Although the mGPSC rise and decay times of EE-reared mice were not statistically different from those of controls, they were consistently faster (Table 1), indicative of accelerated maturation of GABAergic neurotransmission in EEreared mice. By $\mathrm{P} 18$, no differences in mGPSC amplitude or frequency (Fig. $1 C, F-H)$ were detected between control and EE-reared mice, consistent with the control group having "caught up" developmentally with the accelerated EEreared group (see Discussion).

Supporting the observed increase in GABAergic transmission, we found significantly higher levels of $\mathrm{GABA}_{\mathrm{A}}$ receptor $\alpha 1$ $\left(\mathrm{GABA}_{\mathrm{A}} \mathrm{R} \alpha 1\right)$ in the synaptosomal fractions of forebrains and hippocampi from EE-reared mice at both P7 and P14 (Fig. 1I,J). Although the synaptosomal preparation has typically been used for purifying excitatory synaptic components, our results showed that it is also effective at enriching for GABAergic synaptic components, as the $\mathrm{GABA}_{\mathrm{A}} \mathrm{R} \alpha 1$ level increased throughout the purification procedure (supplemental Fig. $1 C$, available at www.jneurosci. org as supplemental material), similarly as that of the excitatory
A

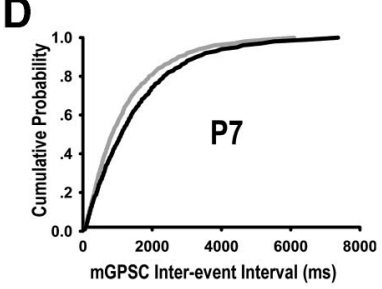

B

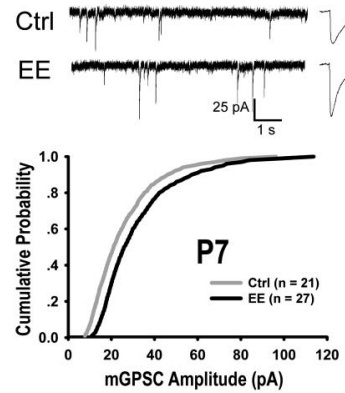

G

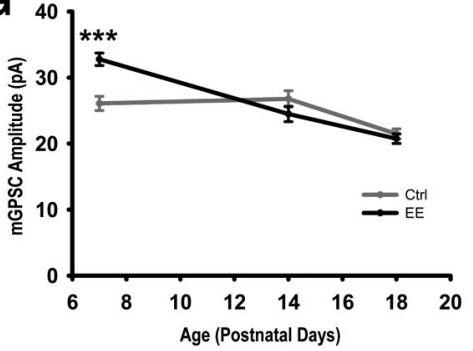

P14

E

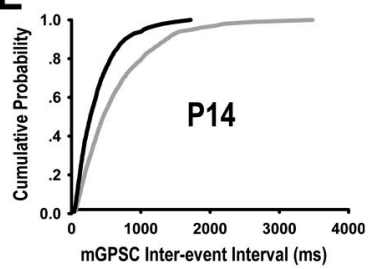

C
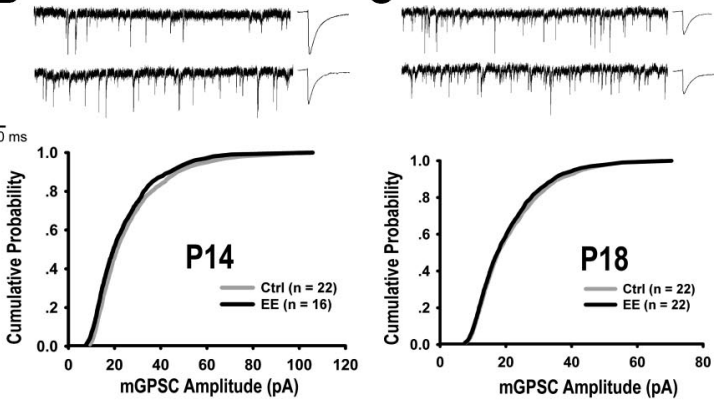

$\mathbf{F}$

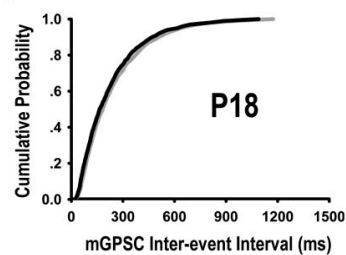

H

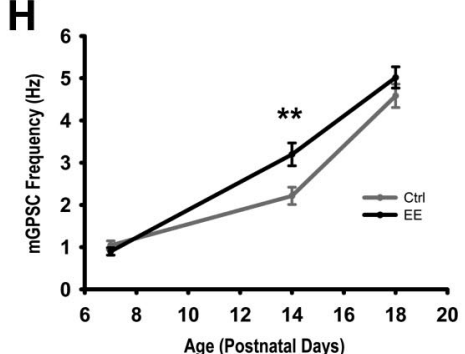

J
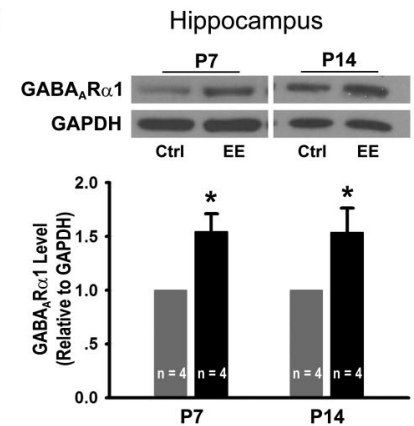

Figure 1. EE rearing promotes GABAergic neurotransmission. $\boldsymbol{A}-\boldsymbol{C}$, Sample mGPSC recordings, averaged mGPSC waveforms, and cumulative mGPSC amplitude distributions from P7 $(p=0.01)(\boldsymbol{A}), \mathrm{P} 14(p=0.31)(\boldsymbol{B})$, and P18 $(p=0.65)(\boldsymbol{C})$ control (Ctrl) and EE-reared mice. $\boldsymbol{D}-\boldsymbol{F}$, Cumulative $\mathrm{mGPSC}$ frequency distributions for P7 $(p=0.44)(\boldsymbol{D}), \mathrm{P} 14(p<0.005)(\boldsymbol{E})$, and P18 $(p=0.40)(\boldsymbol{F})$ mice. G, Developmental course of average mGPSC amplitude: P7 (Ctrl: $26.08 \pm 1.09$ pA, EE: $32.76 \pm 0.94$ pA, $p<0.0001$ ), P14 (Ctrl: $26.77 \pm 1.23 \mathrm{pA}$, EE: $24.49 \pm 1.17 \mathrm{pA}, p=0.20)$, and P18 (Ctrl: $21.47 \pm 0.77 \mathrm{pA}$, EE: $20.75 \pm 0.72 \mathrm{pA}, p=0.50)$. H, Developmental course of average mGPSC frequency: P7 (Ctrl: $1.05 \pm 0.11 \mathrm{~Hz}, \mathrm{EE}: 0.90 \pm 0.09 \mathrm{~Hz}, p=0.30), \mathrm{P} 14$ (Ctrl: $2.20 \pm 0.21 \mathrm{~Hz}, \mathrm{EE}: 3.20 \pm 0.27 \mathrm{~Hz}$, $p=0.005$ ), and P18 (Ctrl: $4.58 \pm 0.28 \mathrm{~Hz}, \mathrm{EE}: 5.02 \pm 0.25 \mathrm{~Hz}, p=0.25) . I$, Representative immunoblots and quantitation of $G A B A_{A} R \alpha 1$ vels from forebrains of $\mathrm{Ctrl}$ and EE-reared mice: $1.23 \pm 0.10(p<0.05)$ at P7 and $1.19 \pm 0.08$ at P14 $(p<0.05)$.J, Immunoblots and quantitation of $\mathrm{GABA}_{A} \mathrm{R} \alpha 1$ from hippocampi of Ctrl and EE mice: $1.55 \pm 0.16(p<0.05)$ at P7 and $1.54 \pm 0.23(p<0.05)$ at P14. In all graphs, error bars represent SEM; ${ }^{*} p<0.05,{ }^{* *} p<0.01,{ }^{* * *} p<0.001$.

postsynaptic density protein PSD95 (Cho et al., 1992). The developmental increase in $\mathrm{GABA}_{\mathrm{A}} \mathrm{R} \alpha 1$ level (Laurie et al., 1992) was also detected in our preparation (supplemental Fig. $1 C$, available at www.jneurosci.org as supplemental material). The increase in postsynaptic $\mathrm{GABA}_{\mathrm{A}} \mathrm{R} \alpha 1$ level, together with a lack of change in the presynaptic measurement of paired-pulse ratios (supplemental Fig. 3, available at www.jneurosci.org as supplemental material), suggests that the enhanced GABAergic synaptic transmission in EE-reared mice is most likely resulting from postsynaptic changes. 
Table 1. Kinetics of mGPSCs in control and EE-reared mice from P7 to P18

\begin{tabular}{|c|c|c|c|c|c|c|c|}
\hline & \multicolumn{3}{|l|}{ Control } & \multicolumn{3}{|l|}{ EE } & \multirow[b]{2}{*}{$p$ (Control versus EE) } \\
\hline & Average \pm SEM & $n$ & $p$ & Average \pm SEM & $n$ & $p$ & \\
\hline \multicolumn{8}{|c|}{$10-90 \%$ Rise time (ms) } \\
\hline P7 & $2.2 \pm 0.3$ & 21 & & $1.6 \pm 0.1$ & 27 & & $=0.05$ \\
\hline P14 & $1.3 \pm 0.1$ & 22 & $<0.01$ (versus P7) & $1.2 \pm 0.1$ & 16 & $<0.01$ (versus P7) & $=0.30$ \\
\hline P18 & $0.9 \pm 0.04$ & 22 & $<0.01$ (versus P14) & $0.8 \pm 0.04$ & 22 & $<0.01$ (versus P14) & $=0.21$ \\
\hline \multicolumn{8}{|c|}{ Decay time (ms) } \\
\hline P7 & $17.5 \pm 1.0$ & 21 & & $16.2 \pm 0.5$ & 27 & & $=0.21$ \\
\hline P14 & $13.7 \pm 0.5$ & 22 & $<0.01$ (versus P7) & $13.4 \pm 1.0$ & 16 & $<0.01$ (versus P7) & $=0.79$ \\
\hline P18 & $10.4 \pm 0.4$ & 22 & $<0.001$ (versus P14) & $9.7 \pm 0.3$ & 22 & $<0.001$ (versus P14) & $=0.18$ \\
\hline
\end{tabular}

A
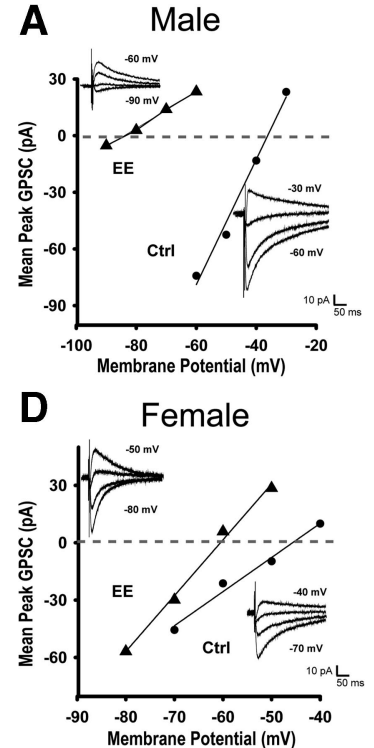

B

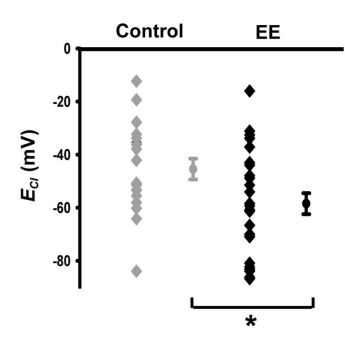

E

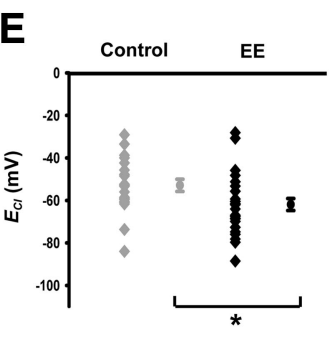

C

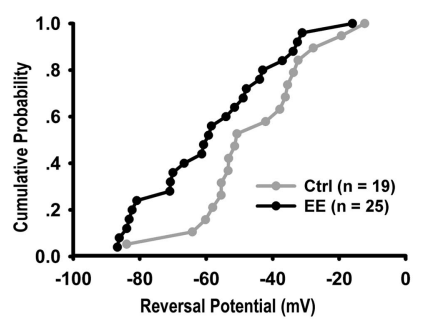

$\mathbf{F}$

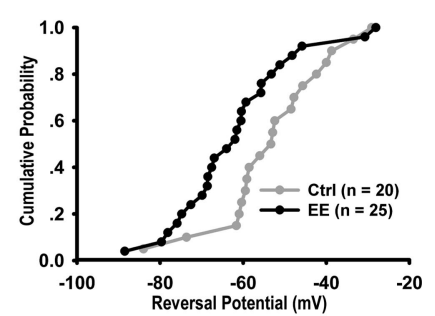

G

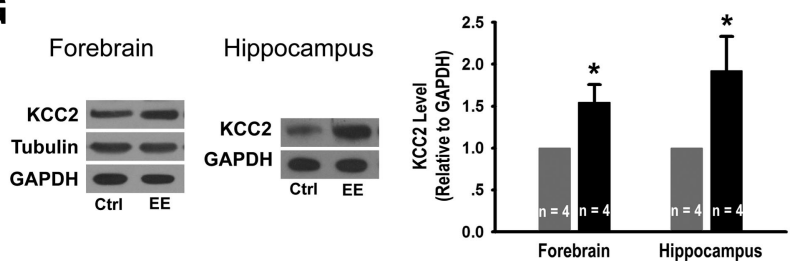

Figure 2. EE rearing accelerates switch of GABA action from excitation to inhibition. $A, D$, Examples of $I-V$ relationship for evoked GABA $R$ currents from $P 9$ control (Ctrl) and EE male $(\boldsymbol{A})$ or female $(\boldsymbol{D})$ mice, together with sample traces recorded at $10 \mathrm{mV}$ intervals. $\boldsymbol{B}, E_{C \mathrm{C}}$ estimated from evoked $\mathrm{GABA}_{\mathrm{A}} \mathrm{R}$ currents in male $\mathrm{Ctrl}(-45.4 \pm 3.9 \mathrm{mV}, n=19)$ and EE mice $(-58.4 \pm 4.0 \mathrm{mV}$, $n=25, p<0.05)$. Each data point represents a single neuron, with the average shown to the right of each group. $C$, Cumulative probability plot of data presented in $\boldsymbol{B}, p<0.05$. $\boldsymbol{E}, E_{\mathrm{Cl}}$ for female $\mathrm{Ctrl}(-52.9 \pm 2.9 \mathrm{mV}, n=20)$ and EE mice $(-61.9 \pm 2.8 \mathrm{mV}$, $n=25, p<0.05$ ). $\boldsymbol{F}$, Cumulative probability plot of data presented in $\boldsymbol{E}, p<0.05$. G, Immunoblots and quantitation of KCC2 levels from Ctrl and EE mice: forebrain $(1.54 \pm 0.21, p<0.05)$ and hippocampus $(1.92 \pm 0.41, p<0.05)$.

\section{EE rearing accelerates the developmental switch of GABA action}

Since GABA has been reported to act as a trophic factor that regulates its own developmental switch from excitation to inhibition in cultured neurons (Ganguly et al., 2001), we asked whether natural stimulation through EE rearing can accelerate this transition. Using gramicidin-perforated whole-cell recording, we measured the reversal potential of evoked GPSCs $\left(E_{\mathrm{Cl}}\right)$ in CA1 pyramidal cells of P9 control and EE-reared mice. Consistent with previous reports (Nunez and McCarthy, 2007; Galanopoulou, 2008), we found $E_{\mathrm{Cl}}$ to be more hyperpolarized in females $(-52.9 \pm 2.9 \mathrm{mV})$ compared with males $(-45.4 \pm 3.9$ $\mathrm{mV})$. Importantly, $E_{\mathrm{Cl}}$ was significantly more hyperpolarized in EE-reared pups in both males (EE: $-58.5 \pm 4.0 \mathrm{mV}$, control:
$-45.4 \pm 3.9 \mathrm{mV}, p<0.05)$ (Fig. $2 A-C$ ) and females (EE: $-61.9 \pm 2.8 \mathrm{mV}$, control: $-52.9 \pm 2.9 \mathrm{mV}, p<0.05)$ (Fig. $2 \mathrm{D}$ $F)$, as well as for all cells combined (EE: $-60.4 \pm 2.4 \mathrm{mV}$, ctrl: $-49.3 \pm 2.5 \mathrm{mV}$, $p<0.01)$. Thus, pyramidal cells in EEreared pups exhibited lower intracellular chloride and, therefore, more inhibitory GABAergic responses. Consistently, we observed higher protein levels of the $\mathrm{K}^{+}$$\mathrm{Cl}^{-}$transporter KCC2, a key player in the developmental switch from GABAmediated excitation to inhibition (BenAri, 2002; Owens and Kriegstein, 2002), in the membrane fraction of forebrain or hippocampal preparations from P7 EEreared mice (Fig. 2G). Together, these results demonstrate that $\mathrm{EE}$ rearing accelerates the developmental switch of GABA action from excitation to inhibition. Postnatal EE rearing enhances
glutamatergic neurotransmission
Whole-cell recording of glutamatergic
synaptic transmission was made from P7
to P18. As shown in Figure $3 A-D$, the
mean mEPSC amplitude decreased from
P7 to P18 in both control and EE-reared
mice, consistent with a previous report
(Hsia et al., 1998). Importantly, mEPSC
amplitude (Fig. $3 B, D$ ) (EE: $13.51 \pm 0.54$
pA, Control: $11.77 \pm 0.29$ pA, $p<0.05$ )
and spontaneous EPSC amplitudes (sup-
plemental Fig. 4, available at www.
jneurosci.org as supplemental material)
were significantly higher in EE-reared mice at P14. No significant differences in mEPSC frequency and kinetics were observed between the two groups (Fig. $3 E-H$, supplemental Table 1, available at www.jneurosci.org as supplemental material).

Western blotting of the synaptosomal fraction showed that the levels of excitatory synaptic component postsynaptic density 95 (PSD95), AMPA receptor subunit GluR2, and NMDA receptor subunit NR2B were higher in EE-reared mice than controls at both P7 and P14 (Fig. 4A-B), similar to previous reports using adult rodents (Tang et al., 2001; Nithianantharajah et al., 2004; Naka et al., 2005). Consistent with the observed increases in the protein levels of both NMDA and AMPA receptors, the AMPA to NMDA ratio of evoked synaptic responses remained unchanged 
A

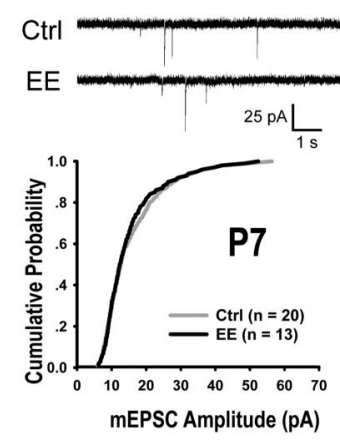

E

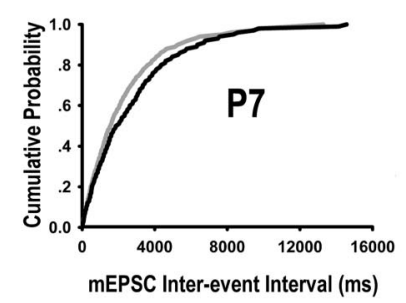

B

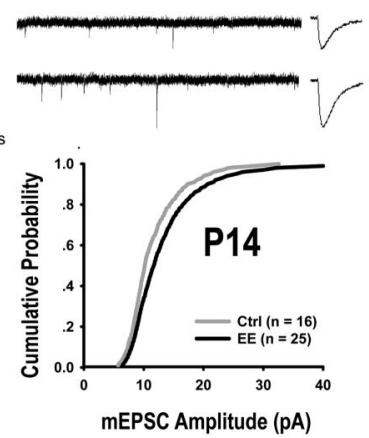

F

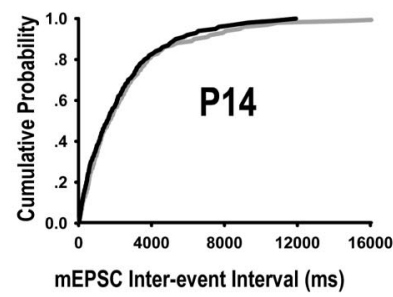

C
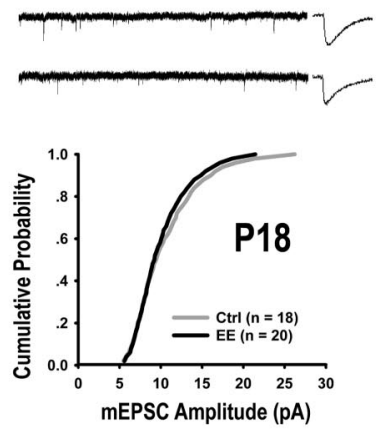

G

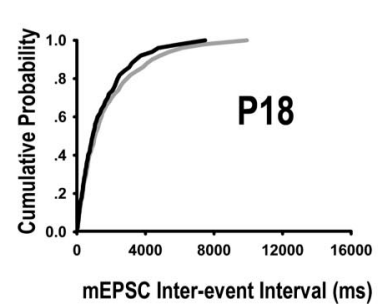

D

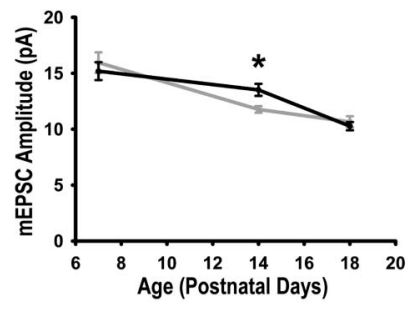

H

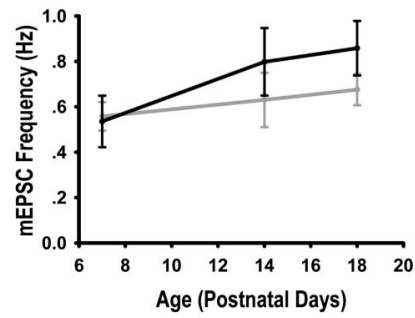

Figure 3. EE rearing promotes glutamatergic neurotransmission at P14. $A-C$, Sample $m E P S C$ recordings, averaged $m E P S C$ waveforms, and cumulative $m E P S C$ amplitude distributions of P7 $(p=0.66)(\boldsymbol{A}), \mathrm{P} 14(p<0.05)(\boldsymbol{B})$, and P18 $(p=0.54)(\boldsymbol{C})$ mice. $\boldsymbol{D}$, Developmental course of average mEPSC amplitude from P7 (Ctrl: $15.95 \pm 0.92 \mathrm{pA}, \mathrm{EE}: 15.19 \pm 0.91 \mathrm{pA}, p=$ 0.58), P14: Ctrl: $11.77 \pm 0.29$ pA, EE: $13.51 \pm 0.54$ pA, $p<0.05$ ) and P18 (Ctrl: $10.65 \pm 0.49$ pA, EE: $10.27 \pm 0.37$ pA, $p=0.54$ ) mice. E-G, Cumulative distributions of mEPSC frequencies from P7 $(p=0.23)(\boldsymbol{E}), \mathrm{P} 14(p=0.37)(\boldsymbol{F})$, and P18 $(p=0.37)(\boldsymbol{G})$ mice. $\boldsymbol{H}$, Developmental course of average mEPSC frequency from P7 (Ctrl: $0.56 \pm 0.06 \mathrm{~Hz}, \mathrm{EE}: 0.54 \pm$ $0.11 \mathrm{~Hz}, p=0.86), \mathrm{P} 14(\mathrm{Ctrl}: 0.63 \pm 0.12 \mathrm{~Hz}, \mathrm{EE}: 0.80 \pm 0.15 \mathrm{~Hz}, p=0.43)$ and P18 (Ctrl: $0.68 \pm 0.07 \mathrm{~Hz}$, EE: $0.86 \pm 0.12 \mathrm{~Hz}, p=0.21)$ mice. Ctrl, Control.

A

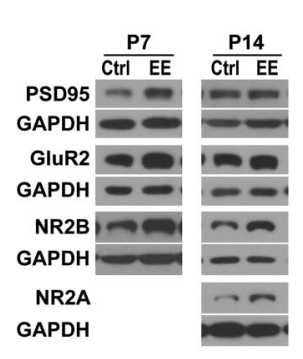

C

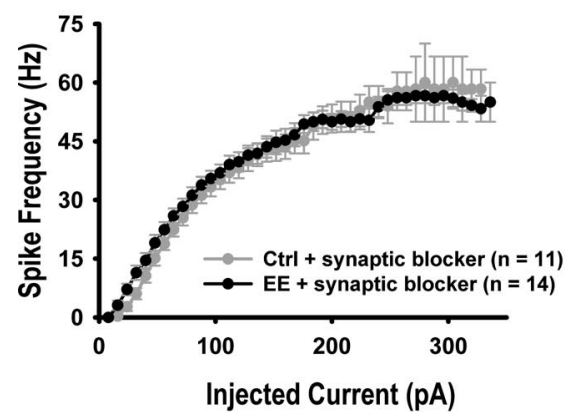

Forebrain

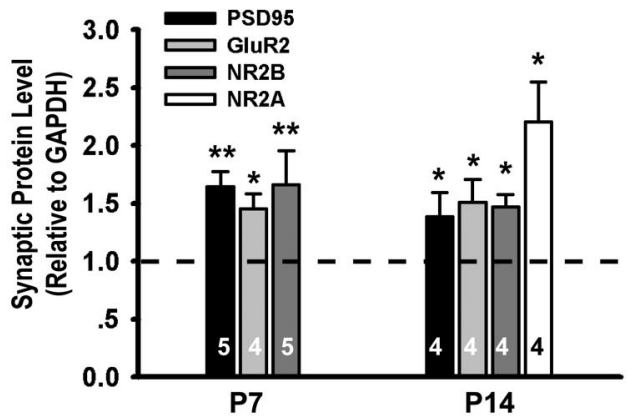

D

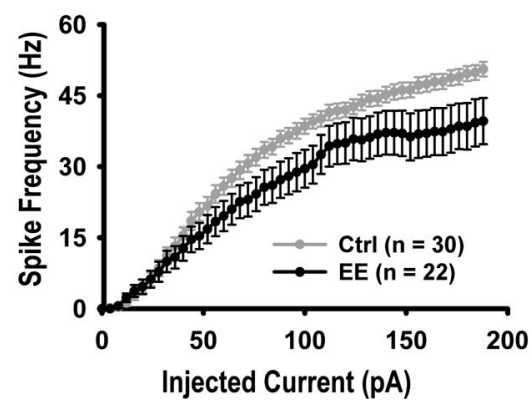

B Hippocampus

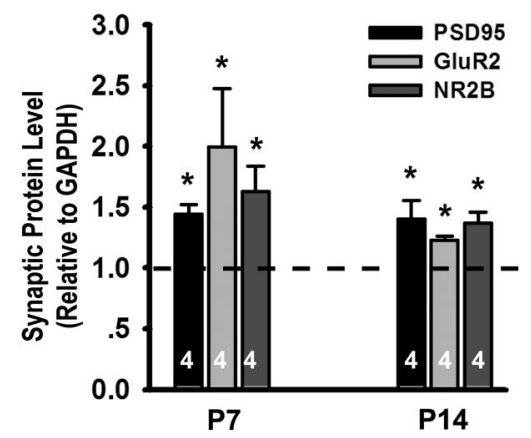

$\mathbf{E}$

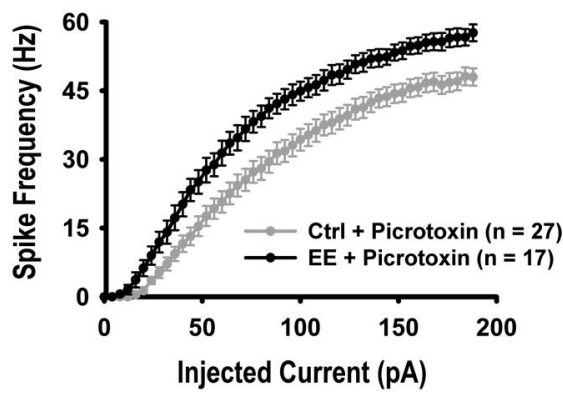

Figure 4. Effects of EE rearing on glutamatergic synapses and neuronal firing. $A$, Immunoblots and quantitation of excitatory synapse components from forebrains of P7 (PSD95:1.65 $\pm 0.13, p<$ 0.01; GluR2: $1.45 \pm 0.13, p<0.05 ;$ NR2B: $1.66 \pm 0.30, p<0.01$ ) and P14 (PSD95: $1.38 \pm 0.21, p<0.05 ;$ GluR2: $1.51 \pm 0.20, p<0.05 ;$ NR2B: $1.47 \pm 0.11, p<0.05 ;$ NR2A: $2.20 \pm 0.35, p<$ 0.05 ) mice. $B$, Quantitation from hippocampi of P7 (PSD95: $1.44 \pm 0.08, p<0.05$; GluR2: $2.00 \pm 0.48, p<0.05$; NR2B: $1.63 \pm 0.21, p<0.05$ ) and P14 (PSD95: $1.40 \pm 0.15, p<0.05$; GluR2: $1.23 \pm 0.03, p<0.05 ;$ NR2B: $1.37 \pm 0.09, p<0.05$ ) mice. C, Plot of spike frequency in response to current pulses of increasing amplitude in P14 mice in the presence of synaptic blockers (D-APV, $\mathrm{NBQX}$, and picrotoxin), $p=0.88$. D, Neurons from EE-reared mice showed reduced firing in the absence of synaptic blockers, $p<0.05$. $E$, Neurons from EE-reared mice showed elevated firing in the presence of $\mathrm{GABA}_{\mathrm{A}} \mathrm{R}$ antagonist, $p<0.05$. Ctrl, Control. 
in P14 mice (EE: $1.23 \pm 0.12$, control: $1.12 \pm 0.12, p=0.53$ ). There were also no significant changes in NMDA receptormediated conductances (supplemental Fig. 5, available at www. jneurosci.org as supplemental material).

Since changes in intrinsic excitability have been reported to be an activity-dependent plasticity mechanism (Zhang and Linden, 2003; Frick and Johnston, 2005), we examined this parameter in control and EE-reared mice by measuring, in the presence of synaptic blockers, the frequency of action potential fired in response to depolarizing current injections. No significant differences in the intrinsic excitability of control and EE-reared mice were detected at P14 (Fig. 4C). Interestingly, when recordings were made in the absence of synaptic blockers, a shift to the right, indicating decreased overall excitability, was observed in EE-reared mice (Fig. 4D). The situation was reversed when GABAergic transmission was blocked (Fig. $4 E$ ). These findings are consistent with our above-described results in showing elevated GABAergic neurotransmission in EE-reared mice at P14.

\section{Discussion}

Using EE rearing of neonatal mice pups as a paradigm, we investigated the effects of natural environmental stimulations during early development on GABAergic and glutamatergic synapses. We found enhancement of GABAergic transmission as early as P7, measured as increases in mGPSC amplitude and $\mathrm{GABA}_{\mathrm{A}} \mathrm{R} \alpha 1$ levels. Furthermore, we observed accelerated transition of GABA action from excitation to inhibition, measured as a shift in $E_{\mathrm{Cl}}$ and an increase in KCC2 level. Increased glutamatergic neurotransmission was detected in EE-reared mice at the later stage of P14, when increase in GABAergic neurotransmission persisted. Together, these results provide evidence for the important role of natural environmental stimulation during the neonatal period in enhancing early GABA action and promoting the development of GABAergic and glutamatergic synapses.

Because of the complexity of developmental changes in the amplitude, frequency, and kinetics of mPSCs, it is somewhat difficult to summarize the effects of EE rearing on neural circuit development. Based on our results, we would like to argue for accelerated maturation of GABAergic and glutamatergic synapses through EE rearing for the following reasons. First, enrichment accelerates the developmental switch of GABA action from excitation to inhibition (Fig. 2). Second, the developmental increase in $\mathrm{GABA}_{\mathrm{A}} \mathrm{R} \alpha 1$ level is enhanced in EE-reared mice (Fig. $1 I-J)$. Third, although the kinetics of mGPSCs from EE-reared mice are not significantly different from those of controls, they are generally faster (Table 1), consistent with the developmental maturation trend. Fourth, in-line with an increase in mGPSC frequency during development, we observed significant increases in mGPSC frequency in EE-reared mice at P14 (Fig. $1 \mathrm{H}$ ), an effect that plateaued out by $\mathrm{P} 18$, at which point presumably the control mice have caught up developmentally. In the case of glutamatergic synapses, the increase in mEPSC amplitude at P14 (Fig. 3D), which plateaued out by P18, also likely represents accelerated maturation of glutamatergic synapses in EEreared mice, because of the following: (1) a higher level of excitatory synapse components is observed in EE-reared mice at both P7 and P14 (Fig. 4A,B); and (2) the mEPSC frequency is slightly elevated in EE-reared mice compared with controls at P14 and P18 (Fig. 3H).

An important finding of our study is the observation of changes in synaptic transmission following EE rearing as early as P7 (Fig. $1 A, G$ ). To our knowledge, this is the earliest time point at which natural stimulation has been reported to affect synaptic function in the mammalian brain. Although pups at this age are incapable of exploring their environment voluntarily, immediate sensory stimulations were provided via textured bedding material and novel odors in the cage. Furthermore, additional maternal care (Liu et al., 2000; Sale et al., 2004, 2009) and the presence of many other pups may also contribute toward the complex natural stimulation that they receive. Our observation of changes in GABAergic transmission at P7 (Fig. $1 A, G$ ), 1 week before increases in glutamatergic transmission (Fig. $3 B, D$; supplemental Fig. 4, available at www.jneurosci.org as supplemental material), is consistent with the earlier appearance of GABAergic synaptic currents in the rodent hippocampus (Ben-Ari et al., 1989). By P14, when GABA action had mostly switched to inhibitory (supplemental Fig. 2C, available at www.jneurosci.org as supplemental material), GABAergic neurotransmission remains elevated in EE-reared mice and is available to balance the increased glutamatergic transmission. By accelerating the maturation of GABAergic synapses before that of glutamatergic synapses, EE rearing promotes neural circuit maturation in a balanced manner.

The neurotransmitter GABA is also a trophic factor that plays important roles in many aspects of neural development, including cell proliferation, neuronal migration, dendrite arborization, synapse formation, and activity-dependent neural circuit development (Ben-Ari, 2002; Owens and Kriegstein, 2002; Akerman and Cline, 2007). EE rearing, by elevating GABAergic transmission early (Fig. $1 A, G$ ), allows the trophic functions of GABA to affect neural circuit development, such as accelerating its own transition from excitation to inhibition. The early elevation in GABAergic transmission could also play a role in mediating increases in excitatory synaptic transmission (Fig. $3 B, D$; supplemental Fig. 4, available at www.jneurosci.org as supplemental material), since molecular manipulations that interfere with the normal transition of GABA action can lead to defects in glutamatergic synaptic transmission (Akerman and Cline, 2006; Ge et al., 2006). Given the important role of GABA in neural development, its accelerated maturation through EE rearing provides a means by which natural environmental stimulations promote the development of neural circuits.

\section{References}

Akerman CJ, Cline HT (2006) Depolarizing GABAergic conductances regulate the balance of excitation to inhibition in the developing retinotectal circuit in vivo. J Neurosci 26:5117-5130.

Akerman CJ, Cline HT (2007) Refining the roles of GABAergic signaling during neural circuit formation. Trends Neurosci 30:382-389.

Banks MI, Hardie JB, Pearce RA (2002) Development of GABA receptormediated IPSCs in hippocampus. J Neurophysiol 88:3097-3107.

Ben-Ari Y (2002) Excitatory actions of GABA during development: the nature of the nurture. Nat Rev Neurosci 3:728-739.

Ben-Ari Y, Cherubini E, Corradetti R, Gaiarsa JL (1989) Giant synaptic potentials in immature rat CA3 hippocampal neurones. J Physiol 416:303-325.

Bennett EL, Diamond MC, Krech D, Rosenzweig MR (1964) Chemical and anatomical plasticity brain. Science 146:610-619.

Cancedda L, Putignano E, Sale A, Viegi A, Berardi N, Maffei L (2004) Acceleration of visual system development by environmental enrichment. J Neurosci 24:4840-4848.

Cho KO, Hunt CA, Kennedy MB (1992) The rat brain postsynaptic density fraction contains a homolog of the Drosophila discs-large tumor suppressor protein. Neuron 9:929-942.

Dunning DD, Hoover CL, Soltesz I, Smith MA, O’Dowd DK (1999) GABA A receptor-mediated miniature postsynaptic currents and alpha-subunit expression in developing cortical neurons. J Neurophysiol 82:3286-3297.

Flavell SW, Greenberg ME (2008) Signaling mechanisms linking neuronal 
activity to gene expression and plasticity of the nervous system. Annu Rev Neurosci 31:563-590.

Fox K, Wong RO (2005) A comparison of experience-dependent plasticity in the visual and somatosensory systems. Neuron 48:465-477.

Frick A, Johnston D (2005) Plasticity of dendritic excitability. J Neurobiol 64:100-115.

Galanopoulou AS (2008) Dissociated gender-specific effects of recurrent seizures on GABA signaling in CA1 pyramidal neurons: role of $\mathrm{GABA}_{\mathrm{A}}$ receptors. J Neurosci 28:1557-1567.

Ganguly K, Schinder AF, Wong ST, Poo M (2001) GABA itself promotes the developmental switch of neuronal GABAergic responses from excitation to inhibition. Cell 105:521-532.

Ge S, Goh EL, Sailor KA, Kitabatake Y, Ming GL, Song H (2006) GABA regulates synaptic integration of newly generated neurons in the adult brain. Nature 439:589-593.

Hallett PJ, Collins TL, Standaert DG, Dunah AW (2008) Biochemical fractionation of brain tissue for studies of receptor distribution and trafficking. Curr Protoc Neurosci Chapter 1:Unit 1.16.

Hensch TK (2005) Critical period plasticity in local cortical circuits. Nat Rev Neurosci 6:877-888.

Hollrigel GS, Soltesz I (1997) Slow kinetics of miniature IPSCs during early postnatal development in granule cells of the dentate gyrus. J Neurosci 17:5119-5128.

Hsia AY, Malenka RC, Nicoll RA (1998) Development of excitatory circuitry in the hippocampus. J Neurophysiol 79:2013-2024.

Huntsman MM, Huguenard JR (2000) Nucleus-specific differences in $\mathrm{GABA}_{\mathrm{A}}$-receptor-mediated inhibition are enhanced during thalamic development. J Neurophysiol 83:350-358.

Jiang B, Huang ZJ, Morales B, Kirkwood A (2005) Maturation of GABAergic transmission and the timing of plasticity in visual cortex. Brain Res Brain Res Rev 50:126-133.

Laurie DJ, Wisden W, Seeburg PH (1992) The distribution of thirteen $\mathrm{GABA}_{\mathrm{A}}$ receptor subunit mRNAs in the rat brain. III. Embryonic and postnatal development. J Neurosci 12:4151-4172.

Liu D, Diorio J, Day JC, Francis DD, Meaney MJ (2000) Maternal care, hippocampal synaptogenesis and cognitive development in rats. Nat Neurosci 3:799-806.

Luo J, Wang Y, Yasuda RP, Dunah AW, Wolfe BB (1997) The majority of $N$-methyl-D-aspartate receptor complexes in adult rat cerebral cortex contain at least three different subunits (NR1/NR2A/NR2B). Mol Pharmacol 51:79-86.

Matsumoto T, Rauskolb S, Polack M, Klose J, Kolbeck R, Korte M, Barde YA (2008) Biosynthesis and processing of endogenous BDNF: CNS neurons store and secrete BDNF, not pro-BDNF. Nat Neurosci 11:131-133.

Morales B, Choi SY, Kirkwood A (2002) Dark rearing alters the develop- ment of GABAergic transmission in visual cortex. J Neurosci 22:80848090.

Naka F, Narita N, Okado N, Narita M (2005) Modification of AMPA receptor properties following environmental enrichment. Brain Dev 27:275278.

Nithianantharajah J, Hannan AJ (2006) Enriched environments, experiencedependent plasticity and disorders of the nervous system. Nat Rev Neurosci 7:697-709.

Nithianantharajah J, Levis H, Murphy M (2004) Environmental enrichment results in cortical and subcortical changes in levels of synaptophysin and PSD-95 proteins. Neurobiol Learn Mem 81:200-210.

Nunez JL, McCarthy MM (2007) Evidence for an extended duration of GABA-mediated excitation in the developing male versus female hippocampus. Dev Neurobiol 67:1879-1890.

Owens DF, Kriegstein AR (2002) Is there more to GABA than synaptic inhibition? Nat Rev Neurosci 3:715-727.

Pham TM, Winblad B, Granholm AC, Mohammed AH (2002) Environmental influences on brain neurotrophins in rats. Pharmacol Biochem Behav 73:167-175.

Poo MM (2001) Neurotrophins as synaptic modulators. Nat Rev Neurosci 2:24-32.

Rosenzweig MR, Bennett EL (1996) Psychobiology of plasticity: effects of training and experience on brain and behavior. Behav Brain Res 78:57-65.

Rosenzweig MR, Bennett EL, Hebert M, Morimoto H (1978) Social grouping cannot account for cerebral effects of enriched environments. Brain Res 153:563-576.

Sale A, Putignano E, Cancedda L, Landi S, Cirulli F, Berardi N, Maffei L (2004) Enriched environment and acceleration of visual system development. Neuropharmacology 47:649-660.

Sale A, Berardi N, Maffei L (2009) Enrich the environment to empower the brain. Trends Neurosci 32:233-239.

Tang YP, Wang H, Feng R, Kyin M, Tsien JZ (2001) Differential effects of enrichment on learning and memory function in NR2B transgenic mice. Neuropharmacology 41:779-790.

van Praag H, Kempermann G, Gage FH (2000) Neural consequences of environmental enrichment. Nat Rev Neurosci 1:191-198.

van Praag H, Schinder AF, Christie BR, Toni N, Palmer TD, Gage FH (2002) Functional neurogenesis in the adult hippocampus. Nature 415:10301034.

Xu C, Zhao MX, Poo MM, Zhang H (2008) $\mathrm{GABA}_{\mathrm{B}}$ receptor activation mediates frequency-dependent plasticity of developing GABAergic synapses. Nat Neurosci 11:1410-1418.

Zhang W, Linden DJ (2003) The other side of the engram: experiencedriven changes in neuronal intrinsic excitability. Nat Rev Neurosci 4:885900 